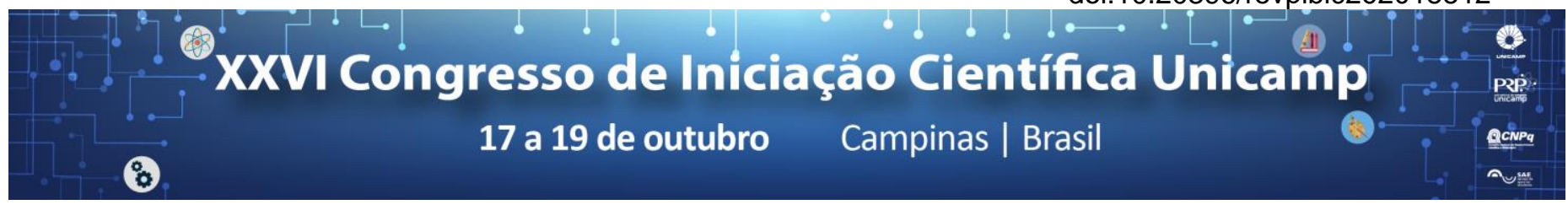

\title{
Avaliação da atividade prebiótica do amido da fruta-do-lobo (Solanum lycocarpum).
}

\author{
Leonardo C. B. Lauretti, Ana P. Pereira, Verônica O. Alvarenga, Anderson S. Sant'Ana, Glaucia M. Pastore.
}

\section{Resumo}

À fruta-do-lobo (Solanum lycocarpum St. Hill) têm sido atribuídas propriedades hipocolesterolêmicas, anti-inflamatória e hipoglicemiantes, apresentendo, portanto, potencial para ser considerado um alimento fonte de prebióticos. Como os estudos sobre os compostos bioativos da fruta-do-lobo e do seu amido ainda são escassos, este trabalho teve por objetivo a caracterização do amido da fruta do lobo e avaliação da sua atividade prebiótica.

\section{Palavras-chave:}

Amido resistente, prebiótico, AGCC.

\section{Introdução}

Fruta-do-lobo é uma fruta típica do cerrado brasileiro utilizada na medicina popular como sedativo, diurético, antiepiléptico, antiespasmódico e antiinflamatório. Seu amido é utilizado como agente hipoglicemiante e hipocolesterolêmico devido a presença de amido resistente ${ }^{1}$.

Amido resistente é a soma total do amido e dos produtos de degradação deste que resistem à digestão no intestino delgado ${ }^{2}$, tornando-se substrato para a fermentação das bactérias colônicas. Os principais produtos resultantes dessa fermentação sãos os ácidos graxos de cadeia curta, que entram no sangue e promovem melhora de algumas funções fisiológicas, tais como redução dos níveis de glicose sanguínea. Portanto, pode ser considerando agente prebiótico.

\section{Resultados e Discussão}

A extração do amido foi realizada de acordo com a Figura 1. Foram utilizados $24 \mathrm{~kg}$ de fruta-do-lobo verde e o rendimento médio foi de $3,7 \pm 0,53 \%$, valor inferior ao relatado por Clerici et al. (2011).
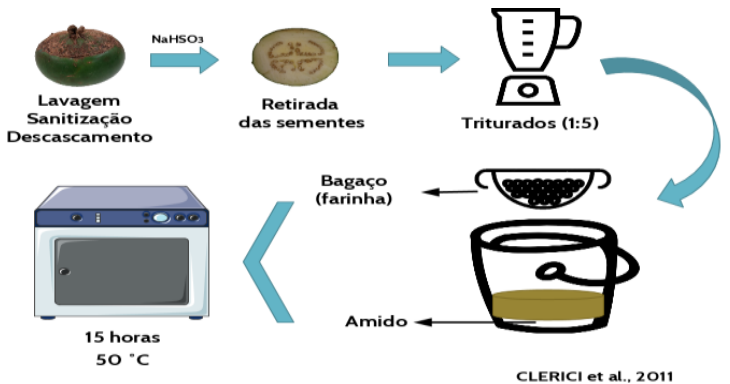

Figura 1. Metodologia extração do amido.

Os valores referentes a composição centesimal do amido da fruta-do-lobo estão representados na Tabela 1.

Tabela 1. Composição centesimal do amido.

\begin{tabular}{lc}
\hline Composição & Amido $(\mathrm{g} / 100 \mathrm{~g})$ \\
\hline Umidade & $8,66 \pm 0,07$ \\
Proteínas & $0,68 \pm 0,02$ \\
Lipídeos & $0,18 \pm 0,014$ \\
Carboidratos & $90,36 \pm 0,0$ \\
Cinzas & $0,12 \pm 0,02$ \\
\hline
\end{tabular}

A atividade prebiótica foi avaliada de acordo com Sousa et al. (2015), com modificações. Foram testadas cinco diferentes cepas: Lactobacillus acidophilus (LA5), Lactobacillus casei (LC01) e Bifidobacterium animalis (BB12) (Christian Hansen, Dinamarca), e Bifidobacterium lactis (BLC1) e Lactobacillus acidophilus (LA3) (Lyofast, Itália), com diferentes concentrações de amido.

Foram selecionados os três micro-organismos que apresentaram a maior taxa de crescimento $(p<0,05 \%)$ e a melhor concentração de amido. De acordo com a Tabela 2, BLC1, LC01 e LA3 apresentaram maior crescimento, todos em concentração $2 \%$.

Tabela 2. Taxa de crescimento dos micro-organismos com diferentes concentrações de amido.

\begin{tabular}{|c|c|c|}
\hline Micro-organismo & Concentração amido (\%) & Taxa crescimento $\left(\mathrm{h}^{-1}\right)$ \\
\hline \multirow[t]{4}{*}{ LA3 } & 0,5 & $0,003 \pm 0,001^{\square}$ \\
\hline & 1,0 & $0,002 \pm 0,001^{\square}$ \\
\hline & 1,5 & $0,003 \pm 0,000^{\mathrm{ab}}$ \\
\hline & 2,0 & $0,003 \pm 0,001^{\mathrm{ab}}$ \\
\hline \multirow[t]{4}{*}{ LCO1 } & 0,5 & $0,005 \pm 0,005^{3 b}$ \\
\hline & 1,0 & $0,002 \pm 0,001^{\square}$ \\
\hline & 1,5 & $0,002 \pm 0,000^{b}$ \\
\hline & 2,0 & $0,003 \pm 0,001^{\square}$ \\
\hline \multirow[t]{4}{*}{ LA5 } & 0,5 & $0,003 \pm 0,000^{3}$ \\
\hline & 1,0 & $0,002 \pm 0,000^{3}$ \\
\hline & 1,5 & $0,003 \pm 0,001^{\mathrm{ab}}$ \\
\hline & 2,0 & $0,004 \pm 0,002^{\mathrm{ab}}$ \\
\hline \multirow[t]{4}{*}{ BB12 } & 0,5 & $0,002 \pm 0,001^{\circ}$ \\
\hline & 1,0 & $0,002 \pm 0,000^{b}$ \\
\hline & 1,5 & $0,002 \pm 0,000^{b}$ \\
\hline & 2,0 & $0,002 \pm 0,000^{b}$ \\
\hline \multirow[t]{4}{*}{ BLC1 } & 0,5 & $0,003 \pm 0,001^{\mathrm{ab}}$ \\
\hline & 1,0 & $0,004 \pm 0,002^{\mathrm{ab}}$ \\
\hline & 1,5 & $0,003 \pm 0,001^{\mathrm{ab}}$ \\
\hline & 2,0 & $0,007 \pm 0,002^{\mathrm{a}}$ \\
\hline
\end{tabular}

Letras diferentes para a mesma coluna apresentam diferença significativa pelo Teste de Tukey $(p<0,05)$.

\section{Conclusões}

É possível concluir que o amido resistente da fruta-do-lobo apresenta compostos que são facilmente metabolizados e podem estimular o crescimento de bactérias benéficas.

\section{Agradecimentos}

Agradeço ao CNPQ pelo suporte financeiro e a doutoranda Ana P. Pereira pelo apoio e incentivo ao longo do projeto.

${ }^{1}$ Rocha, D.A. Caracterização físico-química e química do polvilho da frutado-lobo (Solanum lycocarpum St. Hill.). 2006. Dissertação (Mestrado em Agronomia) - Universidade Federal de Lavras - UFLA, Lavras, 2006.

2 Englyst HN, Kingman SM, Cummings JH. (1992). Classification and measurement of nutritionally importante starch fractions. Eur J Clin Nutr, 46. 33-55. 